\title{
JOGNN CLINICAL ISSUES
}

\section{Informed Consent Issues in Assisted Reproduction}

\author{
Nancy Reame, MSN, PhD, FAAN
}

\begin{abstract}
Given the enormous ethicolegal controversies surrounding the use of assisted reproductive technologies (ART) in the United States, the most important role for nurses may be helping couples and third party participants obtain fully informed consent. The high compensation fees for egg donors may place them at special risk of exploitation. New government and professional guidelines, broader representation on ethics committees, and expanded counseling about risks and benefits can help reduce the potential for litigation and enhance patient autonomy. JOGNN, 28, 331-338; 1999.
\end{abstract}

Accepted: December 1998

In 1997, within the span of a little more than a year, a trio of unrelated medical breakthroughs drew worldwide attention to the stunning advances in reproductive science. The creation of Dolly, the sheep clone in Scotland; a successful birth by a 63year-old, donor-egg recipient from California; and the delivery of live septuplets to a couple in Iowa produced an uproar among scientists and scholars regarding the ethical and social implications of pushing reproductive technology further than anyone had imagined possible. At the same time, a number of even more startling assisted reproductive technologies (ARTs) have emerged, along with a new language among those who make use of them (Table 1). Many of the ARTs involve the use of third party participants, so it is now possible for one child to have as many as five different parents-a sperm donor, an ovum donor, a gestational carrier, and two adoptive (rearing) parents. The new parenting paths and configurations raise profoundly difficult and often disturbing ethical questions, contributing to the sense that the field of assisted reproduction is on fast-forward and out of control.
Although we have only begun to examine and define the long-term implications of these new ways of creating families, it is important for nurses specializing in reproductive health care to stay abreast of major developments and adapt their practice to the changing medicolegal landscape and patient needs in the infertility health care arena. Before the mid-1980s, infertility nursing was unheard of as an advanced practice specialty. Today, given the explosion of knowledge, this new specialty has had to rapidly evolve to keep pace with the unsurpassed challenges of clinical care. In addition, given the growing numbers of healthy volunteers who serve as egg donors and gestational carriers, it is likely that primary care nurses in obstetric/gynecologic practices, university health clinics, and community health settings increasingly will encounter women seeking advice, counseling, and referrals in such matters.

Although a host of ethical dilemmas have been identified (see Braverman \& English, 1992; Cohen, 1997; Seibel \& Crockin, 1996), it may be most useful to focus on the importance of the informed consent process as a way for nurses to help women navigate through the uncharted waters of assisted reproduction. With this in mind, existing laws and professional guidelines are discussed and recommendations provided regarding how nurses can strengthen their role as patient advocates for couples and third party participants participating in assisted reproduction.

\section{The Sociopolitical Context of Infertility Medicine in the United States}

Much controversy surrounds the status quo of standard medical practice and ethical conduct in infertility care in the United States. The lack of insurance coverage for most infertility treatments 
Innovations in Technologies and Terminology in

In Vitro Fertilization (IVF) and Assisted Reproduction

\section{Technologies}

Intracytoplasmic sperm injection (ICSI): An IVF procedure used to treat male infertility involving the microinjection of a single sperm into the egg cytoplasm

Assisted hatching: The application of chemicals, laser, or mechanic means to create an opening in the zona pellucida to assist implantation of the embryo after IVF

Pre-implantation genetic screening: An experimental technique used to test embryos created through IVF for genetic disorders before their transfer to the uterus.

Postmenopause pregnancy: Pregnancy in a postmenopausal women achieved through the use of IVF with a donor egg from a fertile woman

Immature oocyte cryopreservation and maturation: The retrieval of immature, unstimulated oocytes from a fertile woman for freezing and subsequent in vitro maturation in the laboratory at a later time. Still considered experimental by the American Society for Reproductive Medicine (ASRM)

Reconstructed oocytes (cytoplasmic/nuclear transfer): Experimental techniques involving either the transfer of normal cytoplasm from an egg donor into the egg of an infertile woman or the transplantation of the nucleus of an egg from an infertile woman into an enucleated donor egg. Both techniques are designed to allow the genetic link to the woman's offspring.

Embryo splitting: The separation of blastomeres of an early preimplantation embryo to produce two or more embryos with the same genome for use in preimplantation genetic diagnosis or to reduce the number of IVF treatment cycles. Unlike cloning, this technique does not involve substitution of the entire genome.

2. Terminology

Third party participants: Individuals providing gametes or reproductive services to create offspring for an infertile couple

Collaborative reproduction: The creation of offspring for rearing parent(s) through the use of third party participants or their donated gametes

Embryo/prebirth adoption: The adoption of genetically unrelated embryos after creation through assisted reproduction technologies

Artificial twinning: The practice of raising as social twins genetically unrelated children born close in age as the result of the simultaneous use of infertility treatment and adoption

Posthumous reproduction: The creation of genetically related offspring from gametes obtained from people who have died through the use of IVF technologies and third party participants

Reproductive tourism: Purposeful travel to the United States by citizens of foreign countries for treatment with assisted reproductive technologies that are prohibited in their own country (e.g., compensated surrogacy, egg donation)

has helped create a high-priced, open marketplace driven by consumer demand. In turn, women have been forced to shop around for the best buy, often exposing themselves to inexperienced personnel, misleading pregnancy rates, and risk-related practices, such as the transfer of a high number of embryos or experimental treatments (Aronson, 1998). In the last few years, the public trust has been shaken by acts of negligence and professional misconduct, such as improper disposition of sperm and embryos, money-back guarantees, marketing of unproven fertility techniques, financial incentives to infertility patients for egg-sharing, and excessive com- pensation fees for third party participants (Katz, 1997; Robertson, 1995; Sauer, 1996). Growing numbers of concerned bioethicists (Cohen, 1996; Institute for Science, Law and Technology Working Group, 1998), patient advocates (Aronson, 1998; Reame, 1997; White, 1998), and physicians (Soules, 1996) have called for national reforms and proactive legislation.

Few states regulate the practice of assisted reproduction, and ART treatments are beyond the usual hospital accreditation guidelines and standard medical licensing requirements set by public health departments. A federal law passed in 1992, the Fertility Clinic Success 
Rate and Certification Act, designed to require clinics to report their pregnancy rates to the Centers for Disease Control (CDC) has had a limited and disappointing impact (Katz, 1997). A law that seeks only voluntary compliance, it lacks the authority and budget to validate clinic data or punish those who choose not to report their pregnancy rates or who provide misleading information.

Unlike most other countries, where comprehensive national policies are in place, the practice of ART in the United States is subject only to minimum standards and the voluntary guidelines of its professional organizations, the American Society for Reproductive Medicine (ASRM) and its affiliate, the Society for Assisted Reproductive Technologies. The major focus of these organizations is educational, and they have no regulatory or enforcement power. In addition, not all infertility clinics are members of ASRM. Approximate-

\section{Given the lack of accepted and enforced practice guidelines, the absence of insurance, the lack of laboratory certification, and the high cost of ART, the need for more consumer safeguards is clear.}

ly 300 clinics in the United States are members of ASRM; however, no one knows how many other practitioners provide infertility treatments or serve as broker programs for third party participants because no special licensing laws exist. Currently, the only recourse for women in the event of misconduct is litigation. Thus, given the lack of accepted and enforced practice guidelines, the absence of insurance, the lack of laboratory certification, and the high cost of ART, the need for more consumer safeguards is clear.

\section{The Role of the Institutional Review Board in Informed Consent}

Because there is no federal law that protects subjects participating in research in the United States, institutional review boards (IRBs) play vital roles in protecting human research subjects. Such boards review initial research plans to make certain that potential subjects have adequate opportunity to provide informed consent and are not exposed to unreasonable risk. The boards also are mandated to conduct repeated review of ongoing, approved research to ensure that human subject pro- tections remain in force. However, a recent audit of the IRB process by the Office of the Inspector General in the Department of Health and Human Services (Brown, 1998) found that this is one aspect of IRBs' function that has been shown to vary significantly in quality and comprehensiveness from committee to committee.

According to the audit, IRB reviews of annual progress and protocol amendments often were hurried and superficial. Part of the problem stemmed from heightened work load pressures caused by limited staff and resources, insufficient scientific expertise to assess the results of protocols, limited outside representation from nonscientific or noninstitutional community members, and an overabundance of trust in the investigator to put the subject's well-being before the investigator's self-interests. The report concluded that the lack of effective ongoing reviews of active research was a serious national issue because it compromises the protection of human subjects (Brown, 1998). This finding may be of special concern for subjects involved in assisted reproduction.

\section{Unique Informed Consent Issues for Individuals Undergoing ART Treatments}

The moral principle of autonomy or respect for the individual has been central, not only in biomedical ethics, but also in health care practices for childbearing women. No longer are health care decisions about childbirth, menopause therapies, or breast cancer treatments the sole purview of the physician; shared decision making with the woman, as an active, fully informed participant, is now the norm. However, in the field of assisted reproduction, where competition for patients is intense and the pressure to keep published pregnancy rates high, critics have warned that the process of obtaining informed consent to assisted reproduction is seriously deficient, particularly with respect to the risks associated with multiple births (New York State Task Force on Life and the Law, 1998). RESOLVE, the advocacy group for those experiencing infertility, has acknowledged that given the physical, financial, and emotional stress infertile individuals are experiencing, they may be deceived easily by misleading advertising, so heightened sensitivity and caution on the part of the in vitro fertilization (IVF) practitioner is required (Zeiselman, 1997).

The goal of obtaining adequate informed consent to medical treatment is not to simply obtain a signature on a form. Rather, it is to assist the patient to come to a well-considered judgment about the nature and consequences of the risks and benefits and to understand the merit of proceeding with treatment, even when alternative options are available and might be less risky. In addition, the decision to accept or reject interventions 
should be substantially voluntary and free of coercion (Beauchamp \& Childress, 1994). The American Nurses Association (ANA) code of ethics for nurses (ANA, 1985 ) and the Association of Women's Health, Obstetric and Neonatal Nurses (AWHONN) standards and guidelines for nursing practice in the care of women and newborns (AWHONN, 1998) provide important rules of conduct regarding patient autonomy and the nurse's role as patient advocate. However, the field of assisted reproduction is loaded with unique conditions that require special considerations when helping couples become fully informed about treatment options, health risks, and outcomes. Unique ethical issues that affect the informed consent process in assisted reproduction are discussed here.

\section{Those Affected By ART}

The unit of treatment and research usually is the infertile couple and their gamete donors/gestational carrier. Thus, the consequences of ART frequently apply, not only to those involved directly, but also to the spouses, parents, and children of the third parties, and most importantly to any offspring that may result. Much controversy surrounds the role of health professionals as advocates for the best interests of the unborn children.

\section{The Desire for a Child}

The intense desire to have a child and the primary focus on outcome, almost at any cost, may cause couples to give away patient rights and decision-making authority, even when their chances of success are low. Regardless of the risks to their health, few women decline to pursue infertility treatments. Among 52 women who were receiving ovulation-inducing drugs, $79 \%$ were willing to accept a potential increased risk of ovarian cancer for the benefit of achieving a pregnancy (Rosen et al., 1997). The New York State Task Force on Life and the Law in 1998 conducted an extensive review of IVF consent forms used by infertility clinics in that state and telephone interviews with former patients on the quality and quantity of information presented. The Task Force concluded that the consent process was widely inconsistent and at times seriously flawed. One former IVF recipient commented on her experience regarding the informed consent process for ovarian stimulation:

You have to sign a big long consent concerning the retrieval, but there is a lack of any discussion about the use of the drugs. ... Some doctors were angry even discussing the risk of drugs, saying it was just the press, but I just think a more deliberate discussion would have put it in context (New York State Task Force on Life and the Law, 1998, p. 217).

Table 2 presents the final recommendations of the Task Force (1998) regarding minimum information

\section{TABLE 2}

New York State Recommendations

Regarding Minimum Information Needed

By Infertility Patients for Informed Consent

to Assisted Reproduction

The likelihood that the patient will become pregnant, based on experience at the particular program with patients of comparable age and comparable medical conditions, including the program's most recent published outcome statistics

The anticipated price of the procedure, including charges for procedures and medications not covered in the standard fee

The risks associated with any drugs to be used

The risks associated with egg retrieval and embryo or oocyte transfer

The risks associated with the transfer of multiple embryos or oocytes, including the likelihood of multiple gestation, the possibility that fetal reduction might be recommended as a response to multiple gestation, a clear explanation of the nature of fetal reduction and the associated risks, and the patient's right to participate in decisions about the number of embryos or oocytes to transfer

The reasonable psychologic ramifications of the procedures

The program's experience performing the particular procedure

Alternatives to the procedure, including the alternative of nontreatment

Adapted from New York State Task Force on Life and the Law. (1998, April). Assisted reproductive technologies: Analysis and recommendations for public policy. New York: Author.

needed by infertility patients for informed consent to assisted reproduction.

\section{Hidden Research}

The intense competition among infertility clinics to be the first to offer new procedures has fostered a rush to market of innovative, inadequately tested therapies that may not undergo proper review by IRBs. Because the federal government is prohibited from funding research on human fertilization, IVF research in the United States is conducted mainly by private clinics, where government sanctions and protections are imposed on a voluntary basis. Infertility patients who undergo innovative therapies often are not defined or treated as research subjects, although such technologies may have had only minimal scientific scrutiny. In addition, the patients' medical information and pregnancy outcomes may become data that are analyzed and reported, either as part of the national CDC data base or simply for advertising purposes by the individual clinic. In an effort to control this type of hidden 
research with uninformed subjects, ASRM has issued an opinion report on elements of informed consent, advising that couples be informed about federal reporting requirements and possible contact for follow-up (ASRM Practice Committee Report, 1997).

\section{Informed Consent as a Dynamic Process}

Given the psychodynamics involved in assisted reproduction and the fast-paced nature of scientific discovery in the field, it is especially critical that informed consent be seen as a dynamic process in need of reassessment on an ongoing basis during treatment. For example, couples should be informed that it is possible to change their minds without prejudice at any time until the procedure or experiment actually begins. Egg donors and carriers need to understand they can change theirs mind until the point of transfer (ASRM Practice Committee Report, 1997).

\section{Third Party Compensation}

Unlike other organ donors, gamete donors and gestational carriers are compensated for their service, usually in amounts far exceeding the ordinary fees provided to volunteers in experimental research studies. Critics argue that this serves as inherent coercion to ignore the potential physical and psychologic harms. A recent advertisement in the University of Michigan student newspaper (The Michigan Daily, 1998) offering $\$ 25,000$ to a blonde, blue-eyed college student for egg donation underscores the need to ensure that adequate informed consent is obtained from volunteers who may be overly induced by inappropriate compensation fees to serve as third party participants in assisted reproduction.

\section{Helping Couples Obtain Informed Consent to Assisted Reproduction}

Gladys White (1992), former Director of the Center for Ethics and Human Rights of the American Nurses' Association, has observed that the most important function for the infertility nurse may be facilitating the couple's informed consent to reproductive treatments. Recommendations are provided here for how nurses involved with women and couples making decisions about assisted reproduction can "get up to speed" on these complex issues and become better-informed patient advocates.

\section{Personal Values and Professional Behavior}

Clarify and distinguish between personal and professional values and recognize their impact on decision making and professional behavior. An important first step is to recognize the influence of personal values, religious beliefs, and moral judgments on professional practice. A nurse who was adopted may hold different values about the ethics of assisted reproduction than someone who has a history of infertility. Cultural differences in beliefs about the nature of the family and acceptable reproductive behaviors within marriage also may influence how professionals make decisions in patient care.

\section{Professional Resources and Practice Guidelines}

Use professional resources and practice guidelines. In response to the serious ethical issues that exist in the field of assisted reproduction, a wealth of information is available from health professional, government, and patient advocacy groups to assist the nurse involved in patient counseling or referral. ASRM offers numerous practice guidelines and policy statements on the ethics of such practices as advertising, the number of embryos transferred, and money-back guarantees for IVF treatments. These guidelines can be obtained on the ASRM web page (www.asrm.org). The patient advocacy group, RESOLVE provides a series of consumer guide questions for choosing an infertility clinic and treatment options. The CDC provides the latest pregnancy rate statistics on its web page with important warnings about the proper meaning and interpretation of these statistics (see www.cdc.gov). The Nursing Special Interest Group and the Mental Health Special Interest Group of ASRM have been actively engaged in educating their members about the ethical, legal, and psychosocial implications of assisted reproduction. Each year, special symposia, research papers, luncheon roundtables, and continuing education programs are offered that are geared specifically to nursing and mental health personnel at the annual ASRM meeting. Nurses have been at the forefront in formulating guidelines for assessing informed consent potential and psychologic readiness for egg donation (Table 3).

\section{Laws and Professional Group Positions}

Know your state's laws and the positions of organized medicine and patient advocacy groups. Currently, a patchwork of laws governs various aspects of assisted

\section{urses specializing in reproductive} health care are well positioned to play a central role as patient advocate, counselor, and facilitator of the informed consent process for individuals facing the problem of infertility and its medical treatment. 


\title{
TABLE 3 \\ Questions to Assess the Adequacy of Informed Consent of Egg Donor Volunteers
}

\begin{abstract}
Has counseling (both psychologic and legal) been provided for the donor and husband (if applicable)?

When relevant, has the donor told her parents that she is donating eggs?

If the donor has children, has she discussed the egg donation process with them?

If she has no children, is she aware that she, like 1 in 12 couples in the United States, may encounter infertility when she tries to achieve a family of her own?

Is the donor aware that she will need to take ovulation induction medications, and does she have adequate knowledge of the possible risks and complications from these
\end{abstract} medications?

Is the donor aware that she may be tested for sexually transmitted disease, including human immunodeficiency virus and her status as a carrier for cystic fibrosis and other genetic conditions?

Is the donor aware that her medical costs for complications of ovarian stimulation are the responsibility of the couple and not the physicians or medical clinic?

Is the donor aware of the significant risk of pregnancy during ovulation induction should she not use effective barrier contraception?

Is the donor comfortable with the degree of choice she may or may not have in selecting the recipient?

Is the donor aware that her eggs may go to a single woman, lesbian couple, interracial couple, a woman past menopause, or be implanted in a gestational carrier, and how does she feel about such possibilities?

Does the donor understand that she loses all control and ownership rights to the eggs and any resulting embryos and children after retrieval, even upon the death of the couple?

Is the donor aware that her eggs may be used to make extra embryos, which may be cryopreserved, used for research, or discarded after several years if abandoned by the couple?

What is the meaning of the compensation fee as a financial incentive for egg donation.

How many cycles of donation does the donor intend to volunteer for? Has she been a donor at another clinic?

If the couple is known or related to the donor, is there any coercion, either subtle or explicit, by the couple to proceed with this option?

What are the donor's expectations for future contact with the recipient and the child? Is she aware that any future child may never be aware of its biologic origins?

Is the donor aware that her medical and billing records may be stored indefinitely and make her possibly identifiable as an egg donor to her insurance company and others, despite special coding procedures?

Is the donor aware that her right to privacy and anonymity to any offspring cannot be guaranteed should future laws oblige clinics to reveal identifying information to future children?

Modified from: ASRM Practice Committee Report 1997; Bernstein, 1996; Clapp, 1996.

reproduction, and laws vary widely from state to state. For example, at least 35 states have laws concerning sperm donation, whereas only 5 (Florida, Oklahoma, North Dakota, Texas, and Virginia) regulate egg donation. Compensated surrogacy is prohibited in New York and several other states but protected by the courts in California. Most state regulations relate to parental rights and ownership of gametes and embryos. Only two states, New Hampshire and Virginia, have laws regarding requirements for informed consent. Laws in these states provide for specific disclosure requirements concerning medical and psychologic risks, legal rights and obligations, specific testing protocols for donated gametes, and details about the clinic's success rates (New York State Task Force on Life and the Law, 1998, p. 226). On certain ART practice issues, positions of 
organized medicine and consumer groups may vary. For example, money-back guarantees for failed IVF treatments are viewed as ethically inappropriate by the American Medical Association (1996) but acceptable with some cautions by the ASRM (1998) and the New York State Task Force on Life and the Law (1998). RESOLVE has not taken an official stand but is openly concerned about potential exploitation of consumers (Aronson, 1998).

\section{Ethics Committees}

Work to establish an ethics committee in a private practice. For the clinician in private practice, there is an inherent conflict of interest in the roles of care provider, researcher, and entrepreneur. This needs to be discussed openly among team members and examined for any potential or perceived harm to the patients and third party participants in IVF. There is a growing trend among infertility clinics to establish advisory boards as a way to raise, review, and resolve ethical questions and concerns. Nurses have played key roles in such committees and note their success in increasing staff awareness, resolving situations with no previously established guidelines, and facilitating decision making as a team. They note it is easier for patients and staff to accept decisions made by a committee, rather than by an individual staff member. Multidisciplinary membership of such committees, including knowledgeable consumers and other members of the community, is encouraged (Moore \& Covington, 1996).

\section{Serve on an Institutional Review Board}

Volunteer as a committee member on a local IRB. Most local IRBs have little scientific, clinical, or consumer experience related to human-subject protection issues in IVF research. Bioethicists cite the need for greater attention to the actual lived experience of women undergoing ART procedures as a way to improve the quality of care in ART practice (Tong, 1996). Nurses and mental health professionals who provide the day-to-day care have seldom been invited participants at the policy-building level, but they may be especially aware of the emotional and psychologic fallout from the intrusive and burdensome procedures.

\section{Lobby for Improved Regulations}

Lobby state legislators for improved regulations governing the practice of assisted reproduction and the need for health insurance coverage for ART treatment. Assisted reproduction is here to stay. Since its introduction in 1984, the use of donated eggs has increased more than tenfold (Sauer, 1996). In 1995, approximately 1600 neonates were conceived this way at 163 clinics in the United States (CDC Report, 1997). The demand for third party or collaborative reproduction surely will intensify as success rates for egg donor pregnancy approach $50 \%$ in the first cycle and $90 \%$ after three attempts (Sauer, 1996). A recent study highlighted the important role of health insurance in controlling costs and adverse outcomes in assisted reproduction. In the 14 states in which insurance coverage for infertility treatment is mandated, clinics transferred fewer embryos during ART procedures, resulting in lower multiple birth rates than were seen in programs in states without such mandates (Frankfurter et al., 1998).

In conclusion, while the debate continues among bioethicists, legislators, and organized medicine regarding how to reform the practice of assisted reproduction, the need for consistent, nationwide consumer safeguards remains. Nurses specializing in reproductive health care are well positioned to play a central role as patient advocate, counselor, and facilitator of the informed consent process for individuals facing the problem of infertility and its medical treatment.

\section{Acknowledgments}

The research for this article was supported by grants from the American Nurses' Foundation and the University of Michigan Institute for Research on Women and Gender.

\section{REFERENCES}

American Medical Association. (1996). Code of medical ethics: current opinions with annotations: 1996-1997 editions. Opinion 6.01. Chicago: AMA Press.

American Nurses Association (ANA). (1985). Code for nurses with interpretive statements. Kansas City, MO: Author.

American Society for Reproductive Medicine (ASRM) Practice Committee Report. (1997, June). Elements to be considered in obtaining informed consent for ART. Birmingham, AL: Author.

American Society for Reproductive Medicine (ASRM). (1998). Guidelines for gamete donation and embryo donation. Fertility and Sterility, 70(4;Suppl 3), 1S-13S.

American Society for Reproductive Medicine (ASRM), Ethics Committee. (1998, September). Shared-risk or refund programs in assisted reproduction. Fertility and Sterili$t y, 70(3), 414-415$.

Anonymous. (1998, October 12). Advertisement for egg donor. The Michigan Daily.

Aronson, D. D. (1998). Getting out of the corner. Fertility and Sterility, 70, 623-624.

Association of Women's Health, Obstetric and Neonatal Nurses (AWHONN). (1998). Standards and guidelines for professional nursing practice in the care of women and newborns (5th Ed.). Washington, DC: Author.

Beauchamp, T. L., \& Childress, J. F. (1994). Respect for autonomy. In: Principles of biomedical ethics (4th Ed.) (pp. 120-188). New York: Oxford University Press.

Bernstein, J. (1996). Program design for successful egg donation. In M. M. Seibel \& S. Crockin (Eds.), Family building through egg and sperm donation (pp. 61-72). Boston: Jones and Bartlett. 
Braverman, A., \& English, M. (1992). Creating brave new families with advanced reproductive technologies. NAACOG's Clinical Issues in Perinatial and Women's Health Nursing, 3, 353-363.

Brown, J. G. (1998, June). Institutional review boards: A time for reform. Department of Health and Human Services, Office of the Inspector General. Government Report OEI-01-97-00193. Washington, DC: Government Printing Office.

Clapp, D. (1996). Consumer perspectives on the donor egg option. In M. M. Seibel \& S. Crockin (Eds.), Family building through egg and sperm donation (pp 251-261). Boston: Jones and Bartlett.

Cohen, C. B. (1996). New ways of making babies: The case of egg donation. Bloomington: Indiana Press.

Cohen, C. B. (1997). Unmanaged care: The need to regulate new reproductive technologies in the United States. Bioethics, 11(3-4), 348-365.

Frankfurter, D., Barret, B. C., Alper, M. M., Berger, M. J., Oskkowitz, S. P., Penzias, A. S., Thompson, I. E., \& Reindollar, R. H. (1998). Insurance mandates for IVG coverage effectively lower multiple births per embryo transfer. Fertility and Sterility, 70(Suppl 1), S51.

Institute for Science, Law and Technology Working Group. (1998). ART into science: Regulation of fertility techniques. Science, 281, 651-652.

Katz, M. A. (1997). The role of a federal regulatory agency. Women's Health Issues, 7, 192-194.

Moore, K., \& Covington, S. (1996). Establishing an ethics committee in a private practice. Insights into Infertility; A Newsletter for Infertility Professionals, Summer/Fall, 10-16.

New York State Task Force on Life and the Law. (1998). Assisted reproductive technologies: Analysis and recommendations for public policy (pp. 230). New York: Author.

Reame, N. E. (1997). Remarks before the National Bioethics Advisory Board. Nursing Outlook, 45(3), 143-144.

Robertson, J. A. (1995). The case of the switched embryos. Hastings Center Report, 25(6), 13-19.

Rosen, B., Irvine, J., Ritvo, P., Shapiro, H., Stewart, D.,
Reynolds, K., Robinson, C., Thomas, J., Neuman, J., \& Murray, J. (1997). The feasibility of assessing women's perceptions of the risks and benefits of fertility drug therapy in relation to ovarian cancer risk. Fertility and Sterility, 68, 90-94.

Sauer, M. V. (1996). Oocyte donation: Reflections on past work and future directions. Human Reproduction, 11, 1149-1155.

Seibel, M. M., \& Crockin, S. L. (1996). In M. M. Seibel \& S. Crockin (Eds.), Family building through egg and sperm donation: Medical, legal, and ethical issues. Boston: Jones and Bartlett.

Soules, M. (1996). Now that we have painted ourselves in a corner. Fertility and Sterility, 66, 693-695.

Tong, R. (1997). Nonfeminist and feminist perspectives on artificial insemination and in-vitro fertilization. In: Feminist approaches to bioethics (pp. 156-186). Boulder, CO: Westview Press.

United States Department of Health and Human Services, Centers for Disease Control, National Center for Chronic Disease Prevention and Health Promotion, Division of Reproductive Health. (1997). 1995 Assisted reproductive technology success rate: National summary and fertility clinic report. Atlanta: CDC. www.cdc.gov/nccdphp/drh/arts/index.htm.

White, G. (1998). Crisis in assisted conception: The British approach to an American dilemma. Journal of Women's Health, 7(3), 321-328.

White, G. B. (1992). Understanding the ethical issues in infertility nursing practice. NAACOG's Clinical Issues in Perinatal and Women's Health Nursing, 3, 347-352.

Zeiselman, K. (1997). Infertility, advertising and choice: A consumer advocate's perspective. Women's Health Issues, 7, 180-185.

Nancy Reame is a Professor in the Center for Nursing Research and Research Scientist in the Reproductive Sciences Program at the University of Michigan in Ann Arbor, MI.

Address for correspondence: Nancy Reame, MSN, PhD, Center for Nursing Research, University of Michigan, 400 North Ingalls Building, Suite 2238, Ann Arbor, MI 48109-0482. 